\title{
Metal-Organic Framework-Functionalized Alumina Membranes for Vacuum Membrane Distillation
}

\author{
Jian Zuo and Tai-Shung Chung * \\ Department of Chemical \& Biomolecular Engineering, National University of Singapore, 4 Engineering Drive 4, \\ Singapore 117585, Singapore; chezuoj@nus.edu.sg \\ * Correspondence: chencts@nus.edu.sg; Tel.: +65-6516-6645; Fax: +65-6779-1936
}

Academic Editors: Stephen Gray and Arjen Y. Hoekstra

Received: 26 September 2016; Accepted: 5 December 2016; Published: 8 December 2016

\begin{abstract}
Nature-mimetic hydrophobic membranes with high wetting resistance have been designed for seawater desalination via vacuum membrane distillation (VMD) in this study. This is achieved through molecular engineering of metal-organic framework (MOF)-functionalized alumina surfaces. A two-step synthetic strategy was invented to design the hydrophobic membranes: (1) to intergrow MOF crystals on the alumina tube substrate and (2) to introduce perfluoro molecules onto the MOF functionalized membrane surface. With the first step, the surface morphology, especially the hierarchical roughness, can be controlled by tuning the MOF crystal structure. After the second step, the perfluoro molecules function as an ultrathin layer of hydrophobic floss, which lowers the surface energy. Therefore, the resultant membranes do not only possess the intrinsic advantages of alumina supports such as high stability and high water permeability, but also have a hydrophobic surface formed by MOF functionalization. The membrane prepared under an optimum condition achieved a good VMD flux of $32.3 \mathrm{~L} / \mathrm{m}^{2}$-h at $60^{\circ} \mathrm{C}$. This study may open up a totally new approach for design of next-generation high performance membrane distillation membranes for seawater desalination.
\end{abstract}

Keywords: metal-organic framework (MOF); hydrophobic; membrane distillation; desalination

\section{Introduction}

Metal-organic frameworks (MOFs) are an emerging group of hybrid nano-porous materials [1,2]. Formed by assembling organic linkers and metal molecules into crystalline scaffolds, MOFs have extremely high surface area and porosity among the reported crystalline materials. Their pore size, porosity, functionality, crystal size and morphology can be tailored by properly choosing the organic linkers and metal clusters [3] and controlled via various techniques, such as assisted synthesis or coordination modulation [4-6]. Therefore, MOFs are widely regarded as versatile materials for separation, storage, drug delivery, catalysis, etc. [7-10]. Thousands of MOF structures have been synthesized and their numbers are still growing [11].

Recently, high performance mixed matrix membranes comprising MOF have been prepared by incorporating MOF nano-particles into polymer matrices [12-14]. These membranes exploit the advantages of the unique molecular sieve characteristics of MOF and the good processability of polymers. However, mixed matrix membranes often have defective morphology due to the voids between polymer chains and nano-particles [15-17]. One approach to address this issue is to prepare a continuous MOF layer on top of the supports. On one hand, this eliminates the compatibility problems at interfaces. On the other hand, it allows control over the MOF crystal orientation and membrane surface morphology.

Recently, researchers have made a significant progress in growing MOF on solid supports [18-20]. By controlling MOF orientation, Ben et al. prepared a poly(methyl methacrylate) (PMMA)-supported HKUST-1 (Hong Kong University of Science and Technology) membrane with high separation 
performance for gas mixtures, such as $\mathrm{H}_{2} / \mathrm{CO}_{2}$ [19]. Other support materials have also been employed, including silica, alumina, gold, etc. For example, Tan et al. have grown free-standing MOF layers on porous alumina surfaces [20]. By using lithographic techniques, they obtained MOF layers with different structures, such as needle crystals or mushroom-shaped structures. The resultant MOF surface showed good omniphobicity. These works not only presented different methods for growing MOF on solid supports, but also demonstrated that the surface structure and morphology could be effectively manipulated by tuning the MOF crystals. Thus, the development of MOF as thin surface films with desirable morphology may contribute significantly to preparing smart membranes for various separation applications.

One of the important applications is to develop membranes with super-hydrophobic properties [21,22]. Usually, high liquid repellence can be obtained with nano- or hierarchical roughness that traps air in between the membrane surface and liquid droplets [23-25]. In nature, typical examples of this phenomenon are plant leaves such as the lotus leaf [25], or some insects such as the water strider [26]. The understanding of surface energy and roughness on natural non-wetting surfaces has led to the development of many nature-mimetic surfaces. Tetuja et al. have fabricated super-hydrophobic surfaces with hierarchical roughness by using nanoparticles [27]. In this work, we aim to design nature-mimetic membranes with super-hydrophobic properties for membrane distillation (MD) as seawater desalination. The micro-structured surface formed by MOF crystals may enable us to create super-hydrophobic membranes.

A novel two-step synthetic strategy was adopted in this study to prepare such nature-mimetic hydrophobic membranes; namely, (1) to develop a MOF functionalized surface on alumina tube supports and (2) to introduce perfluoro molecules onto the MOF surface to lower the surface energy, thus increasing hydrophobicity. More specifically, $\mathrm{NH}_{2}$-MIL-53(Al) (MIL: material from Institut Lavoisier) would be grown on the alumina support membrane owing to its good compatibility with the alumina substrate. In addition, its $\mathrm{Al}$ element on the substrate surface could be used as the active sites for MOF growth. Consequently, intergrown MIL-53(Al) crystals would be formed, which not only eliminates the delamination issue but also allows the synthesis of nano- and hierarchical roughness by controlling the aspect ratio of MIL-53(Al) [28]. $\mathrm{NH}_{2}-\mathrm{MIL}-53(\mathrm{Al})$ is an amino derivative of MIL-53(Al), which utilizes 2-amino terephthalic acid as the organic linker. The amino group is of particular interest here because it can react with perfluorooctanoyl chloride to increase the surface hydrophobicity significantly. The detailed reaction mechanisms will be discussed in the results section.

Once hydrophobic membranes with an ultrathin top MOF layer are obtained, the resultant membranes may possess the intrinsic advantages of the alumina support, such as high temperature and pressure resistance, high water permeability [29] and a hydrophobic surface formed by MOF functionalization. Thus, thoroughly investigations are carried out in this work to evaluate if these membranes are suitable for seawater desalination by means of vacuum membrane distillation (VMD) [30-34]. To our best knowledge, this is the first time that MOF-functionalized alumina membranes are used in MD desalination applications. This work may open up new opportunities to design superior membranes for MD and other applications.

\section{Experimental Section}

\subsection{Materials}

The commercial Inocep ${ }^{\circledR}$ alumina tube (average pore size $200 \mathrm{~nm}$, inner diameter $2.7 \mathrm{~mm}$ and outer diameter $3.7 \mathrm{~mm}$, Hyflux Pte Ltd.) was used as the porous support. In addition, 2-aminoterephthalic acid (Sigma Aldrich) was utilized as the organic linker for MOF. Aluminum nitrate and aluminum acetylacetonate supplied by Sigma Aldrich were acquired as the Al sources for MOF growth. Perfluorooctanoyl chloride (Alfa Aesar) was employed in the reaction to increase membrane hydrophobicity. Acetic acid, ethanol and anhydrous tetrahydrofuran (THF) used in the experiments were purchased from Merck. Deionized (DI) water produced by a Milli-Q unit from 
MilliPore with the resistivity of $18 \mathrm{M} \Omega \cdot \mathrm{cm}$ was used as the solvent, while sodium chloride $(\mathrm{NaCl})$ acquired from Merck was to prepare the model seawater.

\subsection{Preparation of MOF-Functionalized Hydrophobic Membranes}

\subsubsection{MOF Growth on the Alumina Support}

The alumina tubes were cut into $\sim 7 \mathrm{~cm}$ length pieces. These pieces were sonicated in a water batch for $20 \mathrm{~min}$ before usage. Then 2-aminoterepthalic acid was firstly weighed and suspended in DI water to make a $1 \mathrm{wt} \%$ solution. Subsequently, acetic acid was added into the solution with a concentration of $1 \mathrm{wt} \%$. The resultant mixture was sonicated for $20 \mathrm{~min}$ to ensure even dispersion. Then, the solution was transferred to a Teflon-lined stainless steel autoclave, and a piece of alumina tube was immersed in it. The autoclave was sealed and placed in an oven at $120^{\circ} \mathrm{C}$ for 3 days to carry out the thermal reaction. After the reaction, the alumina tube was rinsed with ethanol three times and dried in an oven at $60{ }^{\circ} \mathrm{C}$ overnight for later usage. The produced alumina tube was named as the first growth tube.

The first growth tube above was subjected to a second MOF growth step to increase the MOF layer coverage on membrane surface. A $1 \mathrm{wt} \%$ 2-aminoterepthalic acid/water solution was firstly prepared, then an $\mathrm{Al}$ source (aluminum nitrate or aluminum acetylacetonate) of $1 \mathrm{wt} \%$ was added into the solution. The resultant mixture was sonicated for $20 \mathrm{~min}$. Subsequently, the first growth tube was immersed in it. The whole mixture was placed in an oven at $80^{\circ} \mathrm{C}$ for different durations $(50,24,5,1$ or $0.5 \mathrm{~h})$. Lastly, the alumina tube was rinsed with ethanol three times and dried in an oven at $60^{\circ} \mathrm{C}$ overnight. The resultant tube was noted as the second growth tube.

\subsubsection{Growth of the Hydrophobic Floss}

The second growth tube was treated with perfluorooctanoyl chloride for the growth of hydrophobic floss. Firstly, a $5 \mathrm{wt} \%$ perfluorooctanoyl chloride in a THF solution was prepared. The second growth tube was placed into the solution, and the mixture was rest at room temperature for $5 \mathrm{~h}$. After that, the tube was rinsed with ethanol three times and dried in oven at $60^{\circ} \mathrm{C}$ overnight. Figure 1 describes the preparation steps for the MOF-functionalized hydrophobic membrane.

\section{Alumina support}

MOF growth
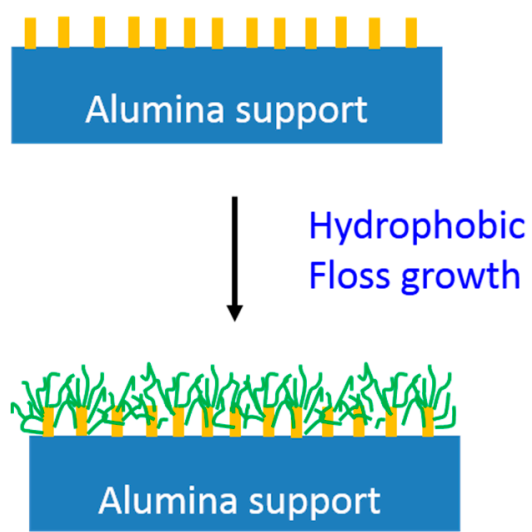

Figure 1. The steps to prepare metal-organic framework (MOF)-functionalized hydrophobic membranes. 


\subsection{Membrane Characterizations}

The membrane morphologies were observed by field emission scanning electron microscopy (FESEM, JEOL, JSM-6700LV). The FESEM samples were prepared by fracturing the alumina tube membranes and coated with platinum using a JEOL JFC-1200 ion sputtering device.

The average pore sizes of the alumina tube membranes before and after MOF functionalization were measured by a CFP-1500 AE capillary flow porometer (PMI, Vista, CA, USA). The sample was prepared by immersing one piece of membranes in a PMI Galwick solution (surface tension of 15.9 dynes $/ \mathrm{cm}$ ) for 1 day to assure total wetting [35]. Then, it was loaded into the porometer for measurements.

Since scanning electron microscope (SEM) cannot observe the differences after perfluoro molecule growth on the second growth tube, the changes in surface chemistry before and after MOF functionalization were measured by X-ray photoelectron spectroscopy (XPS, Kratos AXIS His spectrometer). The surface elemental distribution was detected by X-ray energy dispersive spectrometry (EDX) using an Oxford INCA energy dispersion of X-ray system together with a super ultrathin window (SUTW) connected to a SEM (JEOL, JSM-5600LV) operating at $15 \mathrm{kV}$.

The X-ray diffraction (XRD) patterns of the pristine and MOF-functionalized membranes were obtained using wide angle X-ray diffraction (GADDS WXRD system, Bruker D8 advanced diffractometer) at room temperature. The measurement covers a scan range of $2 \theta=2.0^{\circ}$ to $33.5^{\circ}$ with Ni-filtered $\mathrm{Cu}-\mathrm{K} \alpha$ radiation at a wavelength $\lambda=1.54 \AA$.

The chemical structure changes before and after the growth of hydrophobic floss were analyzed by using Fourier transform infrared-attenuated total reflection (FTIR-ATR; Perkin-Elmer Spectrum 2000 FTIR spectrometer). Each membrane sample was purged with nitrogen for 30 min before the spectra was taken with an average of 16 scans.

The water contact angles of the pristine and MOF-functionalized membranes were measured by a Rame-Hart Contact Angle Goniometer (model, 100-22). Deionized water was dropped onto the membrane surface by a Gilmont micro-syringe. The water contact angle images were recorded.

The liquid entry pressure (LEP) of alumina tube membranes were determined to study the wetting resistance. Figure 2 shows the lab-made setup [36,37]. A $200 \mathrm{~mL}$ stainless steel cylinder was used as the reservoir of salt water containing $3.5 \% \mathrm{NaCl}$. A pressure gauge was installed at the top of the cylinder. Before the measurement, the membrane module was prepared and the outlet of the feed side (lumen side) was sealed. Then, the inlet of the feed side was connected to the reservoir cylinder. During the test, hydraulic pressure was introduced from the compressed nitrogen, and increased with a step of 0.1 bar at an interval of $5 \mathrm{~min}$. The test was run until a drop of water was observed on the shell side of the membrane. The pressure at which the water penetrated through the membrane was determined as the LEP of the membrane sample.

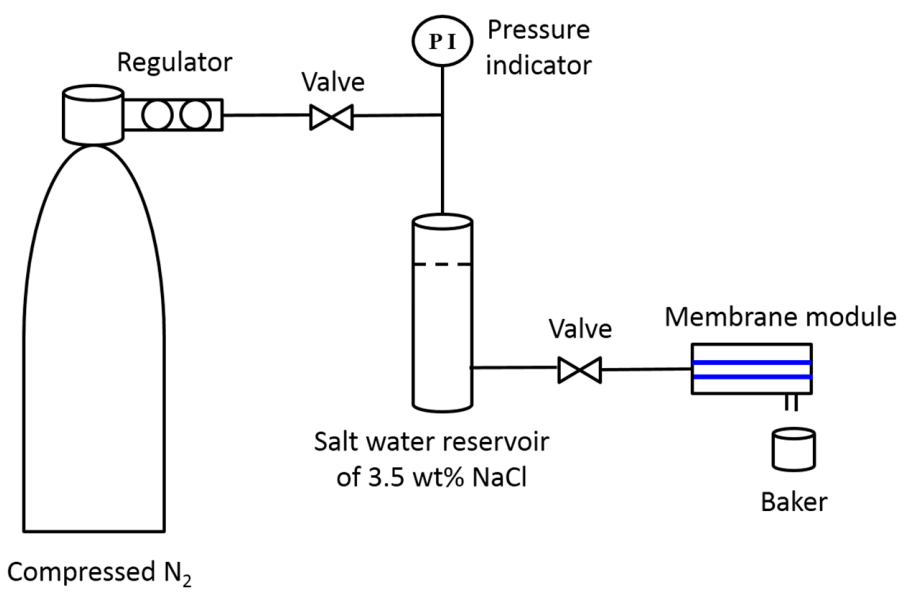

Figure 2. Schematic illustration of the lab-scale setup for liquid entry pressure (LEP) measurements. 


\subsection{VMD Desalination Experiments}

The VMD experiments were carried out to evaluate the desalination performance of MOF-functionalized alumina membranes. In VMD, a pressure difference is created across the membrane by a vacuum pump, which is the driving force for water vapor permeation. Compared to other MD configurations, VMD has the advantages of better thermal efficiency and higher permeation flux [38-40]. However, due to the applied vacuum, the VMD membranes require a higher wetting resistance and radial-direction membrane rigidity than other MD configurations [41]. Thus, the MOF-functionalized alumina membranes are advantageous in VMD applications because of the good mechanical stability and surface hydrophobicity [30,37].

The schematic drawing of a laboratory-scale VMD setup has been described elsewhere [42]. Before running the experiment, the alumina tube membrane sample with an effective membrane area of $4.4 \mathrm{~cm}^{2}$ was mounted into a testing module. Model seawater $(5 \mathrm{~L} 3.5 \mathrm{wt} \% \mathrm{NaCl})$ was used as the feed solution. The feed temperature was controlled at 40,50 and $60{ }^{\circ} \mathrm{C}$ by a heater and circulated to the testing module by a rotary pump at $12 \mathrm{~L} / \mathrm{h}$. On the other hand, the permeate side of the membrane was connected to a vacuum pump, and the pressure was maintained at around 20 mbar. The permeate samples were collected by cold traps immersed in liquid nitrogen. After being conditioned for $0.5 \mathrm{~h}$, samples were taken at an interval of $10 \mathrm{~min}$, and weighed by an accurate balance (A\&D, GR-200). The salinity of the samples was analyzed by a conductivity meter, Lab $960 \mathrm{~m}$ $\left(0-500 \mathrm{~ms} \cdot \mathrm{cm}^{-1}, \pm 0.1 \mu \mathrm{s} \cdot \mathrm{cm}^{-1}\right.$ for the measuring range of $0-200 \mu \mathrm{s} \cdot \mathrm{cm}^{-1}$, SCHOTT instrument). For each condition, at least four samples were collected and the average data were reported. The water permeation flux $\left(J_{w}\right)$ was calculated according to the following equations:

$$
J_{w}=\frac{m}{A \times t}
$$

where $m$ is the mass of the permeate sample collected over time $t$, and $A$ is the effective membrane area. The salt rejection of the membranes was determined from:

$$
\beta=\left(1-\frac{c_{p}}{c_{f}}\right) \times 100 \%
$$

where $c_{p}$ and $c_{f}$ are the $\mathrm{NaCl}$ concentrations in permeate and feed solutions, respectively. During the VMD tests, the membranes had a salt rejection of $99.9 \%$ unless specifically highlighted.

In order to make sure the reproducibility of the alumina tube membranes, repeated VDM tests were performed for all membranes prepared. Deviations in terms of permeation flux were all within $10 \%$. The average data were reported.

\section{Results and Discussion}

\subsection{Growth of MOF on Alumina Membranes}

Figure $3 a, b$ show the FESEM morphology of the inner and outer surfaces of the pristine alumina tube membrane. The inner surface morphology is highly organized and regular, while the outer surface appears to be very disorganized and amorphous. Hence, it may be achievable to grow even MOF coverage on the inner side. Figure $3 c$ displays the inner surface morphology of the first growth tube membrane. Crystals with sizes of 1-3 $\mu \mathrm{m}$ are clearly observed on the membrane surface. The reaction between alumina membrane and 2-aminoterepthalic yielded blocks of $\mathrm{NH}_{2}-\mathrm{MIL}-53(\mathrm{Al})$ microcrystals under the hydrothermal condition. Under closer scrutiny in Figure 3c, these crystals are partially embedded in the membrane surface. This is because that the alumina membrane not only functions as a solid support, but also the $\mathrm{Al}$ source for the growth of MOF. The presence of acetic acid in the reaction solution helps to slowly release the Al source from the membrane surface [23]. Hence, the $\mathrm{NH}_{2}-\mathrm{MIL}-53(\mathrm{Al})$ crystals are intergrown from the alumina surface. Therefore, the MOF 
crystals are immobilized on the membrane surface, and will not delaminate from the surface during actual applications.



Figure 3. Surface morphology of (a) outer surface and (b) inner surface of the pristine ceramic tube; (c) inner surface of the first growth tube.

However, although $\mathrm{NH}_{2}$-MIL-53(Al) crystals are successfully formed, their coverage on alumina surface is not enough for membrane applications. Those uncovered spots are possible defects that may sacrifice membrane separation performance. Thus, a second MOF growth phase is performed to increase the surface coverage. Compared to the first MOF growth phase, the growth in the second MOF phase is much easier as the crystal seeds are already formed. Therefore, a much milder hydrothermal condition is used in this step.

Figure 4 shows the surface morphology after the second growth phase for $50 \mathrm{~h}$ using different aluminum sources of (a) aluminum nitrate and (b) aluminum acetylacetonate. For both cases, large surface coverages are observed because a great number of MOF crystals are formed. The major difference between these two aluminum sources is the shape of the resultant MOF crystals. In the case of aluminum nitrate, flower-like crystals are obtained, where each crystal piece is like a petal of flower. In the case of aluminum acetylacetonate, ordered nanocrystals are formed, which cover the entire substrate surface. These morphological differences are attributed to the different activity of the two aluminum sources $[29,43]$. Since aluminum nitrate has a larger solubility in the reaction solvent of water, more free $\mathrm{Al}$ ions are available in the solution. Therefore, the MOF crystals grow rapidly and radically towards the bulk solution. On the other hand, because aluminum acetylacetonate has lower solubility in water, small MOF crystals are formed due to limited free Al ions around the crystal seeds because of concentration polarization.

Although the MOF morphologies are different, both types have their own advantages and shortcomings. For the formal case, since the petals have an approximately 2-dimensional (2D) structure, they possess a high aspect ratio. This is desirable because it promotes the effective membrane surface area. Moreover, the micro-petals display a larger hierarchical roughness than in the latter case, which may contribute positively to membrane hydrophobicity. However, since the petals are not well aligned, some surfaces are not covered by the crystals. They are potential defective areas for membrane applications. In contrast, the latter case shows a much denser MOF layer structure, which reduces the possibility of membrane defects and membrane wetting. Therefore, both MOF morphologies have 
their unique advantages. Consequently, both second growth tubes may be good precursors for the preparation of hydrophobic membranes.
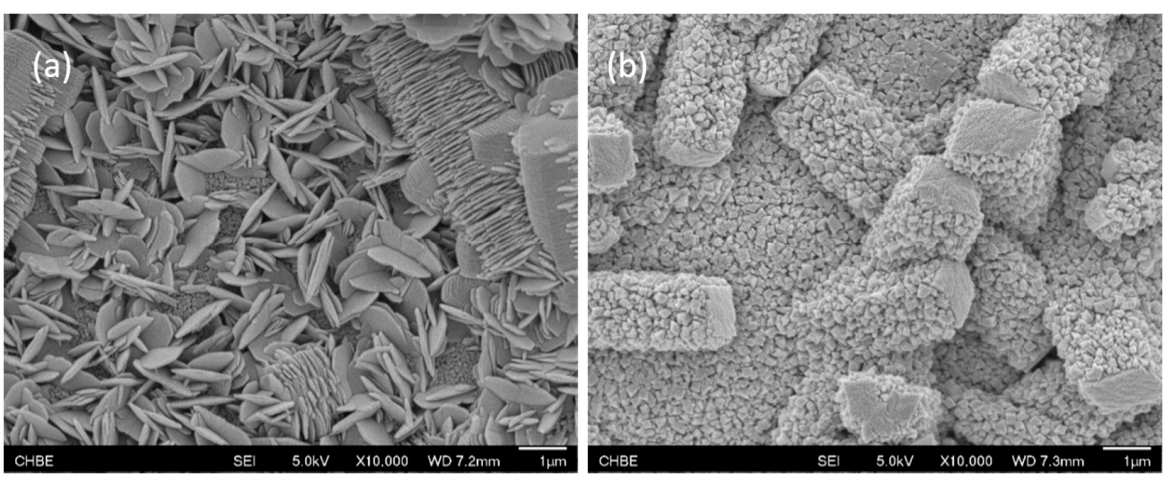

Figure 4. Surface morphology of the second growth tubes from (a) aluminum nitrate and (b) aluminum acetylacetonate sources.

To chemically validate the successful $\mathrm{NH}_{2}$-MIL-53(Al) MOF formation, EDX and XRD measurements are carried out. Figure 5 displays the EDX element distributions on the crystals formed from the two aluminum sources. Both images show a similar atomic ratio among the four major elements, $\mathrm{C}, \mathrm{N}, \mathrm{O}$ and $\mathrm{Al}$, and the small discrepancies may be due to equipment inaccuracy. Generally, $\mathrm{N}$ and $\mathrm{Al}$ elements have a 1:1 atomic ratio, which reflects 1:1 coordination between 2-amino terephthalic acid and $\mathrm{Al}$ ion in the crystal structure. This is in accordance to the $\mathrm{NH}_{2}-\mathrm{MIL}-53(\mathrm{Al})$ chemical formulation. Figure 6 shows the structure formula of the formed $\mathrm{NH}_{2}-\mathrm{MIL}-53(\mathrm{Al})$ framework. One $\mathrm{Al}$ ion is coordinated by one organic linker on the average. The results confirm the successful formation of $\mathrm{NH}_{2}-\mathrm{MIL}-53(\mathrm{Al}) \mathrm{MOF}$ crystals. Figure 7 shows the XRD pattern of the pristine alumina membrane and the second growth MOF tubes from both aluminum sources. The second growth tubes exhibit additional peaks at two theta values around $9^{\circ}, 10^{\circ}$ and $15^{\circ}$. These are the characteristic peaks of MIL-53 crystals at the directions of [101], [200] and [011], respectively [23]. The XRD result further validates the successful formation of MOF crystals after the second growth phase.
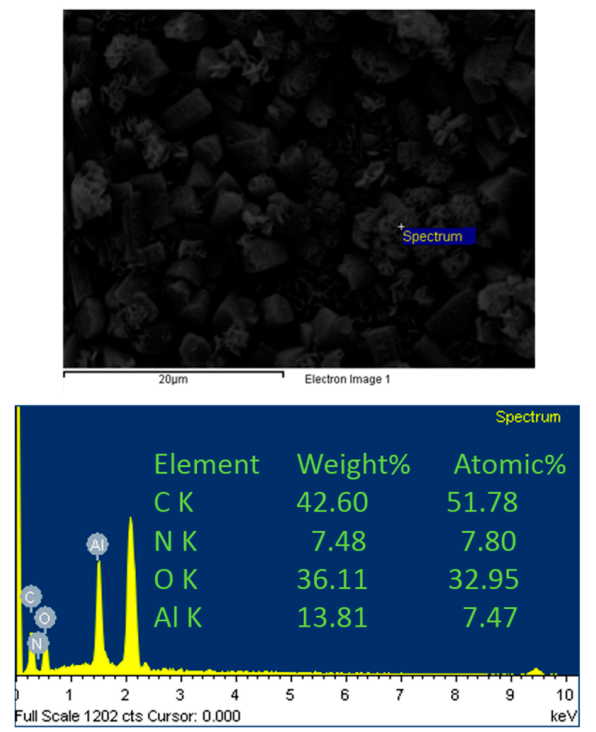

(a)
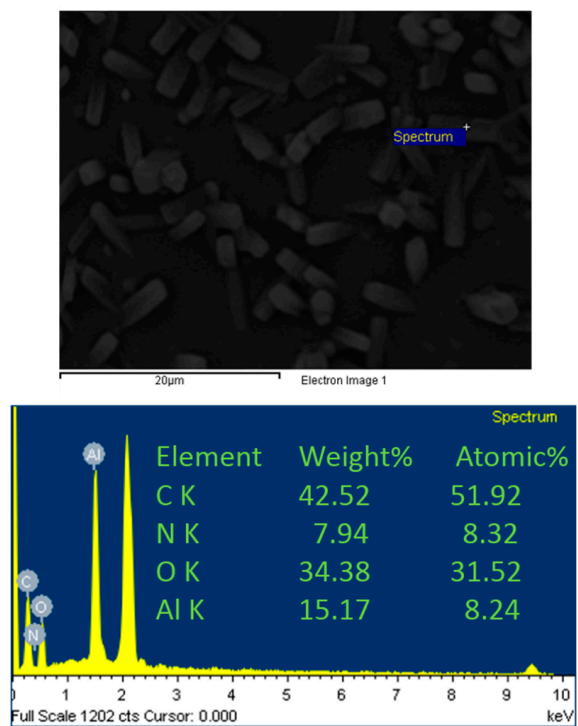

(b)

Figure 5. Energy dispersive spectrometry (EDX) element distributions on the crystals grown from (a) aluminum nitrate and (b) aluminum acetylacetonate sources. 

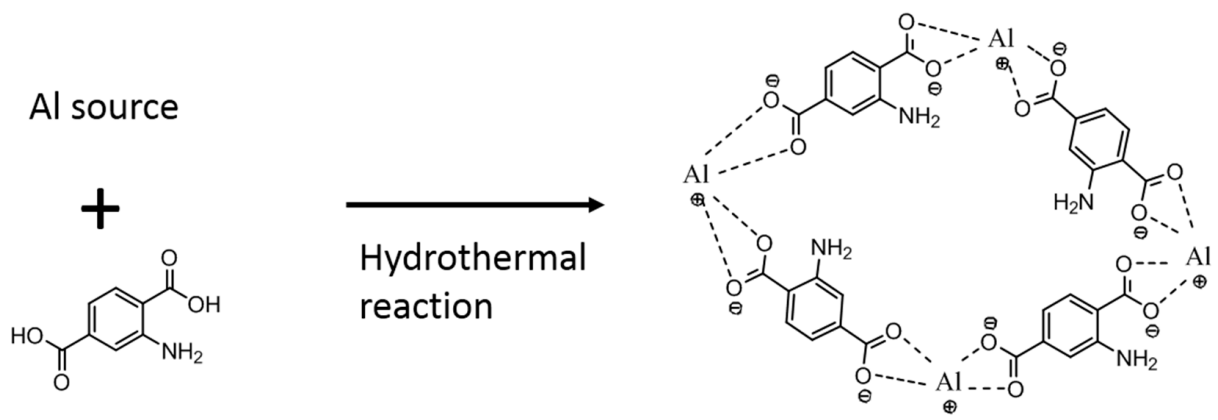

Figure 6. The reaction mechanism to form the $\mathrm{NH}_{2}-\mathrm{MIL}-53(\mathrm{Al})$ framework. MIL: material from Institut Lavoisier.

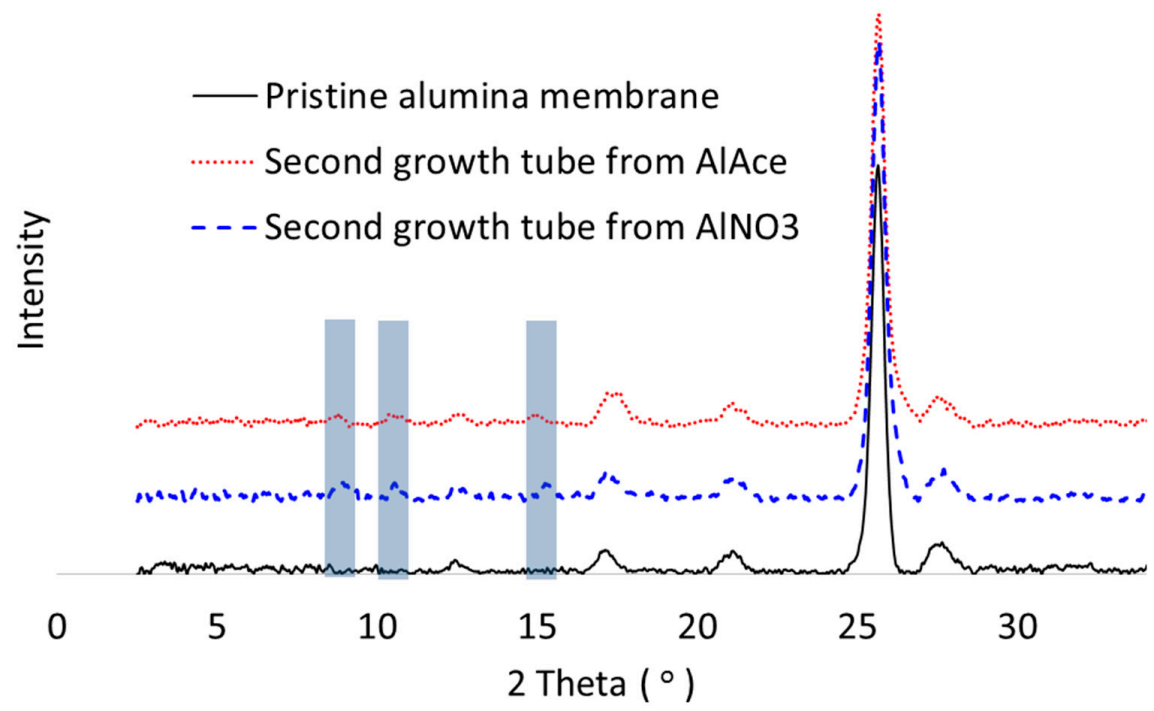

Figure 7. The XRD (X-ray diffraction) patterns of pristine alumina membrane, second growth tube from aluminum acetylacetonate and second growth tube from aluminum nitride.

\subsection{Growth of Hydrophobic Floss}

After the growth of hydrophobic perfluoro molecules on the two $\mathrm{NH}_{2}-\mathrm{MIL}-53(\mathrm{Al})$ functionalized membranes, they were tested under VMD for seawater desalination. Table 1 summarizes their separation performance. The membrane grown from aluminum nitrate has water leakage during the test because the MOF crystals and hydrophobic floss do not cover the membrane substrate fully, as revealed in Figure 4a. Those defective areas allow the seawater to pass through the membrane, and result in the loss of membrane selectivity. In contrast, the membrane prepared from aluminum acetylacetonate shows a flux of $6.2 \mathrm{~L} / \mathrm{m}^{2}-\mathrm{h}$ and a salt rejection of $99.9 \%$ at a feed temperature of $60{ }^{\circ} \mathrm{C}$. Figure 8 presents the cross-section morphology of the resultant membrane. MOF crystals can be clearly observed from the cross-sectional view, which cover the entire membrane surface. This demonstrates the feasibility of preparing MOF-based hydrophobic membranes for MD applications. Therefore, this membrane is further characterized to reveal the membrane characteristics, including chemical structure, pore size, wetting resistance and water contact angle before and after the hydrophobic floss growth. 
Table 1. Vacuum membrane distillation (VMD) performance of MOF membranes prepared from different aluminum sources.

\begin{tabular}{cccc}
\hline Membrane & $\begin{array}{c}\text { Second MOF Growth } \\
\text { Al Source }\end{array}$ & $\begin{array}{c}\text { Second MOF } \\
\text { Growth Time (h) }\end{array}$ & $\begin{array}{c}\text { VMD Flux at } \\
\mathbf{6 0}{ }^{\circ} \mathbf{C}\left(\mathbf{L} / \mathbf{m}^{\mathbf{2}} \mathbf{- h}\right)\end{array}$ \\
\hline Final hydrophobic membrane & Aluminum nitrate & 50 & Leak \\
\hline Final hydrophobic membrane & Aluminum acetylacetonate & 50 & 6.2 \\
\hline
\end{tabular}

Since no differences can be observed by SEM after perfluoro molecule growth, Figure 8 compares the C1s XPS spectra among the pristine alumina membrane, the second growth tube and the final hydrophobic membrane. The pristine membrane displays one peak, which is the reference condition. With the growth of MOF crystals, one additional C1 peak appears at higher binding energy due to the new carbon environment introduced from 2-amino terephthalic acid. Then, two new $\mathrm{C} 1$ peaks appear at around 289 and $291 \mathrm{eV}$ binding energy after the growth of hydrophobic floss. These two high binding energy are the characteristics of carbon atoms that have double bonds or bonds with halogen elements $[44,45]$. Therefore, they can be assigned to $\mathrm{CF}_{2}$ and $\mathrm{CF}_{3}$ in the perfluoro molecule, respectively. In summary, this XPS spectrum signifies the successful grafting of the perfluoro molecules on the MOF-functionalized membrane. In addition, FTIR measurements were also carried out to examine the chemical property changes in the second growth tube and the final hydrophobic membrane. As shown in Figure 9, the CF functional group can be distinguished from the FTIR spectra at the wavenumbers of $1050 \mathrm{~cm}^{-1}$ after the hydrophobic floss growth $[46,47]$. This further validates that the perfluoro molecules have been successfully added to the membrane surface.

Figure 10 displays the evolution of mean pore size change before and after the hydrophobic floss growth measured by PMI porometer. The pristine alumina membrane has a mean flow pore size of $0.19 \mu \mathrm{m}$, which is in agreement with the value provided by the supplier. After being functionalized by MOF crystals, the mean pore size stays roughly the same. This is desirable because the MOF layer does not block the substrate pores and increase transport resistance across the membrane significantly. Nonetheless, some smaller pores are observed in Figure 10b compared to Figure 10a. These smaller pores may result from the growth of MOF crystals, yet they do not change the mean membrane pore size because of the small percentage. Figure 10c displays that the mean pore size is reduced to $0.09 \mu \mathrm{m}$ after the growth of hydrophobic floss. This reflects that the hydrophobic floss has effectively covered the membrane surface and restricted the membrane pore size. This pore size is in the optimal range of VMD membranes because it can generate higher membrane resistance against wetting $[48,49]$.

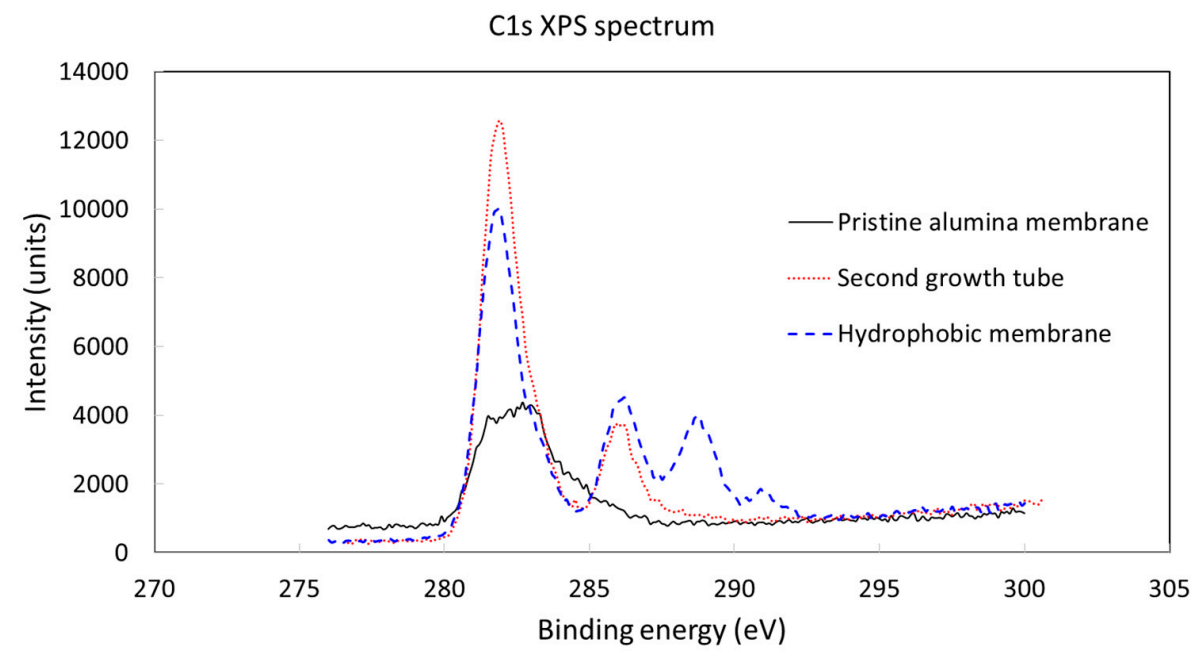

Figure 8. The C1s X-ray photoelectron spectroscopy (XPS) spectra of the pristine alumina membrane, second growth tube from aluminum acetylacetonate and hydrophobic membrane. 




$\begin{array}{llllllllll}600 & 700 & 800 & 900 & 1000 & 1100 & 1200 & 1300 & 1400 & 1500\end{array}$

Figure 9. The Fourier transform infrared (FTIR) spectra of the second growth tube from aluminum acetylacetonate and hydrophobic membrane.
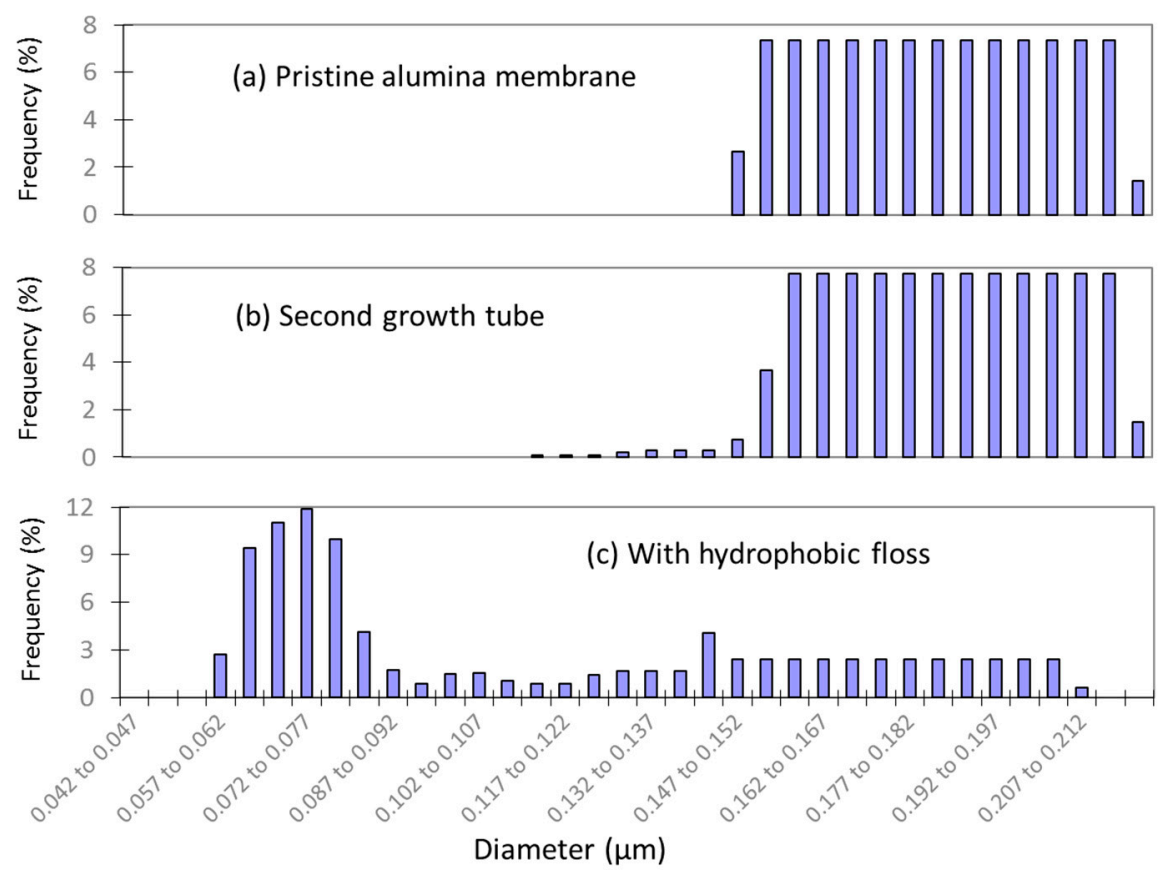

Figure 10. Pore size distributions of the three membranes: (a) pristine; (b) second growth tube from aluminum acetylacetonate and (c) with hydrophobic floss.

The wetting resistance and hydrophobicity of the resultant membrane were experimentally determined. Table 2 lists the LEP values of the membranes before and after hydrophobic floss growth. As expected, the second growth tube is wetted by water without applying any hydraulic pressure. After the hydrophobic treatment, the LEP increases to 3 bar. This is owing to the reduced surface pore size and increased hydrophobicity [50-52]. Figure 11 displays the water contact angles of the tubular membranes. For the pristine alumina membrane, the water droplet quickly wets the inner surface due to its hydrophilicity. Therefore, a water droplet is not captured in Figure 11a. After the growth of the MOF layer, a water droplet can be formed on the inner membrane surface. Nevertheless, the surface is still in the hydrophilic range as the water contact angle is less than $90^{\circ}$. This explains the low LEP value obtained from the second growth tube membrane. Finally, after the hydrophobic floss growth, the water contact angle increases largely. A well-shaped water droplet is clearly observed. However, the exact contact angle is not obtained because of the curved membrane surface. Nonetheless, these 
images explicitly exhibit the increase in membrane hydrophobicity. Once again, the results in wetting resistance and hydrophobicity clearly demonstrate the successful preparation of MOF functionalized hydrophobic membranes.

Table 2. Liquid entry pressures (LEP) of membranes before and after the hydrophobic treatment.

\begin{tabular}{cr}
\hline Membrane & Second MOF G \\
\hline Second growth tube & 50 \\
Second growth tube & 50 \\
\hline
\end{tabular}

(a)

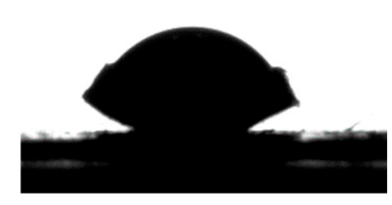

(b)

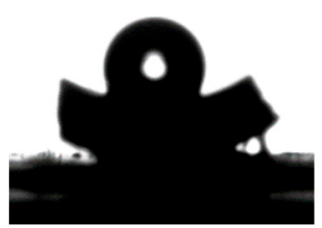

(c)

Figure 11. The water contact angles of the three membranes: (a) pristine (b) second growth tube from aluminum acetylacetonate and (c) with hydrophobic floss.

\subsection{Effect of Second MOF Growth Time on Membrane Performance}

After the attainment of the hydrophobic membrane, its VMD separation performance is further improved. Table 3 tabulates its VMD performance as a function of reaction time for the second MOF growth. The permeation flux increases with decreasing duration for the second MOF growth phase because a looser MOF layer may form in a shorter reaction time. As a result, the vapor transport resistance is reduced and the permeation flux is increased. However, there is a minimum reaction duration to grow sufficient MOF crystals in order to cover the entire membrane surface. Below that duration, defects may remain on the membrane surface. It is noted that when the reaction time is reduced to $0.5 \mathrm{~h}$, the final membrane can only operate at $50{ }^{\circ} \mathrm{C}$. Membrane leakage is observed at the start of the experiment when the feed temperature is set to $60{ }^{\circ} \mathrm{C}$ because higher thermal motion at high feed temperatures may induce defects. Therefore, the minimum reaction duration for the second MOF growth phase is about $1 \mathrm{~h}$ in this case.

Table 3. The effect of second MOF growth duration on VMD performance.

\begin{tabular}{cccc}
\hline Membrane & $\begin{array}{c}\text { Second MOF } \\
\text { Growth Time (h) }\end{array}$ & $\begin{array}{c}\text { VMD Flux at } \\
\mathbf{5 0}^{\circ} \mathbf{C}\left(\mathbf{L} / \mathbf{m}^{\mathbf{2}} \mathbf{- h}\right)\end{array}$ & $\begin{array}{c}\text { VMD Flux at } \\
\mathbf{6 0}^{\circ} \mathbf{C}\left(\mathbf{L} / \mathbf{m}^{\mathbf{2}} \mathbf{- h}\right)\end{array}$ \\
\hline Final hydrophobic membrane & 50 & 4.5 & 6.2 \\
Final hydrophobic membrane & 24 & 5.1 & 8.4 \\
Final hydrophobic membrane & 5 & 9.6 & 17.7 \\
Final hydrophobic membrane & 1 & 16.7 & 32.3 \\
Final hydrophobic membrane & 0.5 & 23.9 & Leak \\
\hline
\end{tabular}

The final membrane prepared from the optimum condition shows a good flux of $32.3 \mathrm{~L} / \mathrm{m}^{2}-\mathrm{h}$ at $60{ }^{\circ} \mathrm{C}$ feed temperature. Table 4 compares it with other VMD membranes made from various materials for seawater desalination [53-58]. The newly designed membrane exhibits a superior flux owing to its unique morphology formed from a nature-mimetic surface structure. The microstructure control of MOF crystals and the hydrophobic floss growth have enabled the novel membrane for VMD applications. Therefore, this work may provide useful guidelines to develop a new type of membranes for MD applications. 
Table 4. A comparison of VMD performance with literature data for seawater desalination.

\begin{tabular}{|c|c|c|c|c|c|}
\hline Author & Membrane & Year & Feed & $\begin{array}{c}\text { Feed Temperature } \\
\left({ }^{\circ} \mathrm{C}\right)\end{array}$ & $\begin{array}{c}\text { Flux } \\
\left(\mathrm{L} / \mathrm{m}^{2}-\mathrm{h}\right)\end{array}$ \\
\hline Khayet and Matsuura [53] & PVDF flat sheet & 2001 & Pure water & 25 & 17.0 \\
\hline Tang et al. [54] & PP flat sheet & 2010 & 3 wt $\% \mathrm{NaCl}$ & 70 & 24.8 \\
\hline Alsaadi et al. [40] & PTFE flat sheet & 2014 & Seawater & 60 & 12.0 \\
\hline Figoli et al. [55] & PVDF hollow fiber & 2014 & $3.5 \mathrm{wt} \% \mathrm{NaCl}$ & 50 & 22.1 \\
\hline Zhang et al. [56] & $\mathrm{Si}_{3} \mathrm{~N}_{4}$ hollow fiber & 2014 & 4 wt $\% \mathrm{NaCl}$ & 80 & 28.3 \\
\hline Sun et al. [57] & PVDF hollow fiber & 2014 & Pure water & 80 & 1.9 \\
\hline This work & MOF-functionalized alumina tube & 2016 & $3.5 w \mathrm{w} \% \mathrm{NaCl}$ & 60 & 32.3 \\
\hline
\end{tabular}

Notes: PVDF: polyvinylidene fluoride; PP: polypropylene; PTFE: polytetrafluoro-ethylene.

\section{Conclusions}

In this work, nature-mimetic membranes with hydrophobic properties were designed by growing and functionalizing MOF with desirable morphology on alumina substrates for seawater desalination via VMD. The following conclusions can be drawn from the current study:

(1) $\mathrm{NH}_{2}$-MIL-53(Al) MOF crystals have been successfully formed on alumina supports via hydrothermal reaction. The alumina substrate functions not only as a solid support, but also provides the $\mathrm{Al}$ sites for MOF growth. Thus, the crystals were intergrown from the support surface and immobilized on the surface.

(2) Different MOF morphologies were achieved through the manipulation of different alumina sources in the second growth phase. The micro-petal crystal morphology from aluminum nitrate had a 2D-like structure, which possessed a high aspect ratio. However, the substrate surface was not fully covered by these crystals due to the distance among the petals. On the other hand, the ordered nanocrystals morphology from aluminum acetylacetonate covered the entire substrate surface and was able to reduce the membrane defects.

(3) Hydrophobic membranes with better wetting resistance were produced after the growth of hydrophobic floss on the MOF functionalized surface. The LEP value of the newly developed membrane increased from 0 to 3 bars.

(4) The VMD performance was improved through the optimization of reaction time for the second MOF growth phase. A shorter reaction duration results in a looser MOF layer, thus the higher permeation flux. The minimum reaction time for the second MOF growth phase was about $1 \mathrm{~h}$. A further shortening the reaction time would lead to membrane defects.

Acknowledgments: This research was funded by the Singapore National Research Foundation under its Energy Innovation Research Program for the project entitled, "Using Cold Energy from Re-gasification of Liquefied Natural Gas (LNG) for Novel Hybrid Seawater Desalination Technologies" (grant number: R-279-000-456-279). We would also gratefully thank Arkema Inc. for providing the PVDF material.

Author Contributions: Both authors contribute equally to this work.

Conflicts of Interest: The authors declare no conflict of interest.

\section{Abbreviations}

ATR

DI

EDX

FESEM

FTIR

HKUST

LEP

MD

MIL

MOF attenuated total reflection

Deionized

energy dispersive spectrometry

field emission scanning electron microscopy

Fourier transform infrared

Hong Kong University of Science and Technology

liquid entry pressure

membrane distillation

Materials of Institut Lavoisier

metal-organic framework 


$\begin{array}{ll}\mathrm{NaCl} & \text { sodium chloride } \\ \text { PE } & \text { polyethylene } \\ \text { PMMA } & \text { poly(methyl methacrylate) } \\ \text { PMI } & \text { porometer } \\ \text { PP } & \text { polypropylene } \\ \text { PTFE } & \text { polytetrafluoro-ethylene } \\ \text { PVDF } & \text { polyvinylidene fluoride } \\ \text { SEM } & \text { scanning electron microscope } \\ \text { THF } & \text { tetrahydrofuran } \\ \text { VMD } & \text { vacuum membrane distillation } \\ \text { XPS } & \text { X-ray photoelectron spectroscopy } \\ \text { XRD } & \text { X-ray diffraction } \\ \text { A } & \text { membrane area } \\ \mathrm{c}_{\mathrm{f}} & \text { NaCl concentrations in feed } \\ \mathrm{C}_{\mathrm{p}} & \text { NaCl concentrations in permeate } \\ \mathrm{m} & \text { mass of the permeate sample } \\ \mathrm{J}_{\mathrm{w}} & \text { permeation flux } \\ \mathrm{t} & \text { time } \\ \beta & \text { salt rejection }\end{array}$

\section{References}

1. Long, J.R.; Yaghi, O.M. The pervasive chemistry of metal-organic frameworks. Chem. Soc. Rev. 2009, 38, 1213-1214. [CrossRef] [PubMed]

2. Kitagawa, S.; Kitaura, R.; Noro, S.I. Functional porous coordination polymers. Angew. Chem. Int. Ed. 2004, 43, 2334-2375. [CrossRef] [PubMed]

3. Khan, I.A.; Qian, Y.; Badshah, A.; Nadeem, M.A.; Zhao, D. Highly porous carbon derived from MOF-5 as a support of ORR electrocatalysts or fuel cells. ACS Appl. Mater. Interfaces 2016, 8, 17268-17275. [CrossRef] [PubMed]

4. Jhung, S.H.; Lee, J.H.; Yoon, J.W.; Serre, C.; Ferey, G.; Chang, J.S. Microwave synthesis of chromium terephthalate MIL-101 and its benzene sorption ability. Adv. Mater. 2007, 19, 121-124. [CrossRef]

5. Taylor, K.M.L.; Jin, A.; Lin, W. Surfactant-assisted synthesis of nanoscale gadolinium metal-organic frameworks for potential multimodal imaging. Angew. Chem. Int. Ed. 2008, 47, 7722-7725. [CrossRef] [PubMed]

6. Cho, W.; Lee, H.J.; Choi, G.; Choi, S.; Oh, M.J. Dual changes in conformation and optical properties of fluorophores within a metal-organic framework during framework construction and associated sensing event. Am. Chem. Soc. 2014, 136, 12201-12204. [CrossRef] [PubMed]

7. Nalaparaju, A.; Zhao, X.S.; Jiang, J.W. Biofuel purification by pervaporation and vapor permeation in metal-organic frameworks: A computational study. Energy Environ. Sci. 2011, 4, 2107-2116. [CrossRef]

8. Zhao, Y.; Seredych, M.; Zhong, Q.; Bandosz, T.J. Superior performance of copper based MOF and aminated graphite oxide composites as $\mathrm{CO}_{2}$ adsorbents at room temperature. ACS Appl. Mater. Interfaces 2016, 5, 4951-4959. [CrossRef] [PubMed]

9. Chen, B.; Ockwig, N.W.; Millward, A.R.; Contreras, D.S.; Yaghi, O.M. High $\mathrm{H}_{2}$ adsorption in a microporous metal-organic framework with open metal sites. Angew. Chem. Int. Ed. 2005, 44, 4745-4749. [CrossRef] [PubMed]

10. Latroche, M.; Surble, S.; Serre, C.; Mellot-Draznieks, C.; Llewellyn, P.L.; Lee, J.H.; Chang, J.S.; Sung, H.J.; Ferey, G. Hydrogen storage in the giant-pore metal-organic frameworks MIL-100 and MIL101. Angew. Chem. Int. Ed. 2006, 4, 8227-8231. [CrossRef] [PubMed]

11. Ferey, G. Hybrid porous solids: Past, present, future. Chem. Soc. Rev. 2008, 37, 191-214. [CrossRef] [PubMed]

12. Keskin, S.; Sholl, D.S. Selecting metal organic frameworks as enabling materials in mixed matrix membranes for high efficiency natural gas purification. Energy Environ. Sci. 2010, 3, 343-351. [CrossRef]

13. Yang, T.X.; Xiao, Y.C.; Chung, T.S. Poly-/Metal-benzimidazole nano-composite membranes for hydrogen purification. Energy Environ. Sci. 2011, 4, 4171-4180. [CrossRef]

14. Jeazet, H.B.T.; Staudt, C.; Janiak, C. Factors controlling successful formation of mixedmatrix gas separation materials. Dalton Trans. 2012, 41, 14003-14027.

15. Chung, T.S.; Jiang, L.Y.; Li, Y.; Kulprathipanja, S. Mixed matrix membranes (MMMs) comprising organic polymers with dispersed inorganic fillers for gas separation. Prog. Polym. Sci. 2007, 32, 483-507. [CrossRef] 
16. Mahajan, R.; Koros, W.J. Factors controlling successful formation of mixedmatrix gas separation materials. Ind. Eng. Chem. Res. 2000, 39, 2692-2696. [CrossRef]

17. Basu, S.; Cano-Odena, A.; Vankelecom, I.F.J. Asymmetric Matrimid ${ }^{@} /\left[\mathrm{Cu}_{3}(\mathrm{BTC})_{2}\right]$ mixed-matrix membranes for gas separations. J. Membr. Sci. 2010, 362, 478-487. [CrossRef]

18. Zacher, D.; Shekhah, O.; Woll, C.; Fischer, R.A. Thin films of metal-organic frameworks. Chem. Soc. Rev. 2009, 38, 1418-1429. [CrossRef] [PubMed]

19. Ben, T.; Lu, C.; Pei, C.; Xu, S.; Qiu, S. Polymer-supported and free-standing metal-organic framework membrane. Chem. Eur. J. 2012, 18, 10250-10253. [CrossRef] [PubMed]

20. Tan, T.T.Y.; Reithofer, M.R.; Chen, E.Y.; Menon, A.G.; Hor, T.S.A.; Xu, J.; Chin, J.M. Tuning omniphobicity via morphological control of metal-organic framework functionalized surfaces. J. Am. Chem. Soc. 2013, 135, 16272-16275. [CrossRef] [PubMed]

21. Saeki, D.; Nagashima, Y.; Sawada, I.; Matsuyama, H. Effect of hydrophobicity of polymer materials used for water purification membranes on biofilm formation dynamics. Colloids Surf. A Physicochem. Eng. Asp. 2016, 506, 622-628. [CrossRef]

22. Karkhanechi, H.; Rajabzadeh, S.; Nicolo, E.D.; Usuda, H.; Shaikh, A.R.; Matsuyama, H. Preparation and characterization of ECTFE hollow fiber membranes via thermally induced phase separation (TIPS). Polymer 2016, 97, 515-524. [CrossRef]

23. Hou, D.; Wang, J.; Sun, X.; Ji, Z.; Luan, Z. Preparation and properties of PVDF composite hollow fiber membranes for desalination through direct contact membrane distillation. J. Membr. Sci. 2012, 405-406, 185-200. [CrossRef]

24. Rafat, M.; De, D.; Khulbe, K.C.; Nguyen, T.; Matsuura, T. Surface characterization of hollow fiber membranes used in artificial kidney. J. Appl. Polym. Sci. 2006, 101, 4386-4400. [CrossRef]

25. Herminghaus, S. Roughness-induced non-wetting. Europhys. Lett. 2000, 52, 165-170. [CrossRef]

26. Gao, X.; Jiang, L. Water-repellent legs of water striders. Nature 2004, 432, 36. [CrossRef] [PubMed]

27. Tuteja, A.; Choi, W.; Ma, M.; Mabry, J.M.; Mazzella, S.A.; Rutledge, G.C.; McKinley, G.H.; Cohen, R.E. Designing superoleophobic surfaces. Science 2007, 318, 1618-1622. [CrossRef] [PubMed]

28. Chin, J.M.; Chen, E.Y.; Menon, A.G.; Tan, H.Y.; Hor, A.T.S.; Schreyer, M.K.; Xu, J. Tuning the aspect ratio of $\mathrm{NH}_{2}$-MIL-53(Al) microneedles and nanorods via coordination modulation. Cryst. Eng. Commun. 2013, 15, 654-657. [CrossRef]

29. Shi, G.M.; Chung, T.S. Thin film composite membranes on ceramic for pervaporation dehydration of isopropanol. J. Membr. Sci. 2013, 448, 34-43. [CrossRef]

30. Li, B.; Sirkar, K.K. Novel membrane and device for vacuum membrane distillation-based desalination process. J. Membr. Sci. 2005, 257, 60-75. [CrossRef]

31. Tomaszewska, M. Membrane distillation. Environ. Prot. Eng. 1999, 25, 37-47.

32. Garcia-Payo, M.C.; Izquierdo-Gil, M.A.; Fernandez-Pineda, C. Wetting study of hydrophobic membranes via liquid entry pressure measurements with aqueous alcohol solutions. J. Colloid Interface Sci. 2000, 230, 420-431. [CrossRef] [PubMed]

33. Song, Z.W.; Jiang, L.Y. Optimization of morphology and performance of PVDF hollow fiber for direct contact membrane distillation using experimental design. Chem. Eng. Sci. 2013, 101, 130-143. [CrossRef]

34. Zhang, J.; Li, J.D.; Duke, M.; Hoang, M.; Xie, Z.; Groth, A.; Tun, C.; Gray, S. Influence of module design and membrane compressibility on VMD performance. J. Membr. Sci. 2013, 442, 31-38. [CrossRef]

35. Sukitpaneenit, P.; Chung, T.S. Molecular design of the morphology and pore size of PVDF hollow fiber membranes for ethanol-water separation employing the modified pore-flow concept. J. Membr. Sci. 2011, 374, 67-82. [CrossRef]

36. Zuo, J.; Bonyadi, S.; Chung, T.S. Exploring the potential of commercial polyethylene membranes for desalination by membrane distillation. J. Membr. Sci. 2016, 497, 239-247. [CrossRef]

37. Kujawski, W.; Kujawa, J.; Wierzbowska, E.; Cerneaux, S.; Bryjak, M.; Kujawski, J. Influence of hydrophobization conditions and ceramic membranes pore size on the properties in vacuum membrane distillation of water-organic solvent mixtures. J. Membr. Sci. 2016, 499, 442-451. [CrossRef]

38. Lawson, K.W.; Lloyd, D.R. Membrane distillation (review). J. Membr. Sci. 1997, 124, 1-25. [CrossRef]

39. Francis, L.; Ghaffour, N.; Alsaadi, A.S.; Nunes, S.P.; Amy, G.L. Performance evaluation of the DCMD desalination process under bench scale and large scale module operating conditions. J. Membr. Sci. 2014, 455, 103-112. [CrossRef] 
40. Alsaadi, A.; Francis, L.; Amy, G.L.; Ghaffour, N. Experimental and theoretical analyses of temperature polarization effect in vacuum membrane distillation. J. Membr. Sci. 2014, 471, 138-148. [CrossRef]

41. Fan, H.; Peng, Y. Application of PVDF membranes in desalination and comparison of the VMD and DCMD processes. Chem. Eng. Sci. 2012, 79, 94-102. [CrossRef]

42. Wang, P.; Chung, T.S. A new-generation asymmetric multi-bore hollow fiber membrane for sustainable water production via vacuum membrane distillation. Environ. Sci. Technol. 2013, 47, 6272-6278. [CrossRef] [PubMed]

43. Ding, S.B.; Wang, W.; Qiu, L.G.; Yuan, Y.P.; Peng, F.M.; Jiang, X.; Xie, A.J.; Shen, Y.H.; Zhu, J.F. Surfactant-assisted synthesis of lanthanide metal-organic framework nanorods and their fluorescence sensing of nitroaromatic explosives. Mater. Lett. 2011, 65, 1385-1387. [CrossRef]

44. Yun, S.K.; Kim, J.W.; Jung, M.J.; Nho, Y.C.; Kang, P.H.; Lee, Y.S. An XPS study of oxyfluorinated multiwalled carbon nano tubes. Carbon Lett. 2007, 8, 292-298. [CrossRef]

45. Nanse, G.; Papirer, E.; Fioux, P.; Moguet, F.; Tressaud, A. Fluorination of carbon blacks: An X-ray photoelectron spectroscopy study: I. A literature review of XPS studies of fluorinated carbons. XPS investigation of some reference compounds. Carbon 1997, 35, 175-194. [CrossRef]

46. Zuo, J.; Chung, T.S. Design and synthesis of a fluoro-silane amine monomer for novel thin film composite membranes to dehydrate ethanol via pervaporation. J. Mater. Chem. A 2013, 1, 9814-9826. [CrossRef]

47. Mihaly, J.; Sterkel, S.; Ortner, H.M.; Kocsis, L.; Hajba, L.; Furdyga, E.; Mink, J. FTIR and FT-Raman spectroscopic study on polymer based high pressure digestion vessels. Croat. Chem. Acta 2006, 79, 497-501.

48. El-Bourawi, M.S.; Ding, Z.; Ma, R.; Khayet, M. A framework for better understanding membrane distillation separation process. J. Membr. Sci. 2006, 285, 4-29. [CrossRef]

49. Zhang, J.; Li, J.D.; Duke, M.; Xie, Z.; Gray, S. Performance of asymmetric hollow fiber membranes in membrane distillation under various configurations and vacuum enhancement. J. Membr. Sci. 2010, 362, 517-528. [CrossRef]

50. Chandavasu, C.; Xanthos, M.; Sirkar, K.K.; Gogos, C.G. Fabrication of microporous polymeric membranes by melt processing of immiscible blends. J. Membr. Sci. 2003, 211, 167-175. [CrossRef]

51. Maab, H.; Francis, I.; Al-saadi, A.; Aubry, C.; Ghaffour, N.; Amy, G.; Nunes, S.P. Synthesis and fabrication of nanostructured hydrophobic polyazole membranes for low-energy water recovery. J. Membr. Sci. 2012, 423-424, 11-19. [CrossRef]

52. Tomaszewska, M. Preparation and properties of flat-sheet membranes from poly(vinylidene fluoride) for membrane distillation. Desalination 1996, 104, 1-11. [CrossRef]

53. Khayet, M.; Matsuura, T. Preparation and characterization of polyvinylidene fluoride membranes for membrane distillation. Ind. Eng. Chem. Res. 2001, 40, 5710-5718. [CrossRef]

54. Tang, N.; Jia, Q.; Zhang, H.; Li, J.; Cao, S. Preparation and morphological characterization of narrow pore size distributed polypropylene hydrophobic membranes for vacuum membrane distillation via thermally induced phase separation. Desalination 2010, 256, 27-36. [CrossRef]

55. Figoli, A.; Simone, S.; Criscuoli, A.; Al-Jlil, S.A.; Al Shabouna, F.S.; Al-Romaih, H.S.; Di Nicolo, E.; Al-harbi, O.A.; Drioli, E. Hollow fivers for seawater desalination from blends of PVDF with different molecular weights: Morphology, properties and VMD performance. Polymer 2014, 55, 1296-1306. [CrossRef]

56. Zhang, J.W.; Fang, H.; Wang, J.W.; Hao, L.Y.; Xu, X.; Chen, C.S. Preparation and characterization of silicon nitride hollow fiber membranes for seawater desalination. J. Membr. Sci. 2014, 450, 197-206. [CrossRef]

57. Sun, A.C.; Kosar, W.; Zhang, Y.; Feng, X. Vacuum membrane distillation for desalination of water using hollow fiber membranes. J. Membr. Sci. 2014, 455, 131-142. [CrossRef]

58. Wang, J.W.; Li, L.; Zhang, J.W.; Xu, X.; Chen, C.S. $\beta$-Sialon ceramic hollow fiber membranes with high strength and low thermal conductivity for membrane distillation. J. Eur. Ceram. Soc. 2016, 36, 59-65. [CrossRef]

(C) 2016 by the authors; licensee MDPI, Basel, Switzerland. This article is an open access article distributed under the terms and conditions of the Creative Commons Attribution (CC-BY) license (http:/ / creativecommons.org/licenses/by/4.0/). 